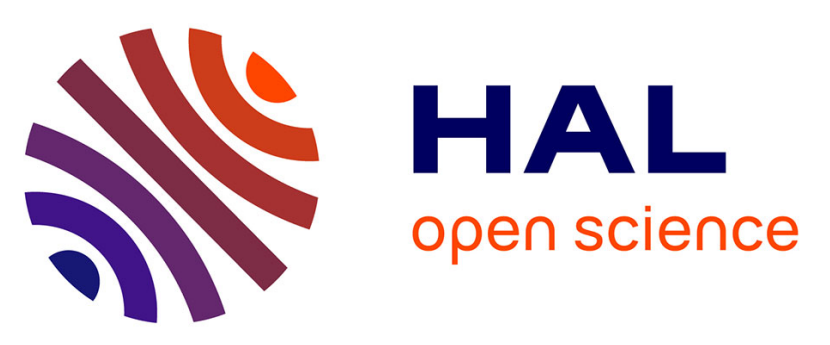

\title{
Mechanical Ventilation-induced Diaphragm Disuse in Humans Triggers Autophagy
}

\author{
Sabah N. A. Hussain, Mahroo Mofarrahi, Ioanna Sigala, Ho Cheol Kim, \\ Theodoros Vassilakopoulos, Francois Maltais, Ion Bellenis, Rakesh \\ Chaturvedi, Stewart B Gottfried, Peter Metrakos, et al.
}

\section{To cite this version:}

Sabah N. A. Hussain, Mahroo Mofarrahi, Ioanna Sigala, Ho Cheol Kim, Theodoros Vassilakopoulos, et al.. Mechanical Ventilation-induced Diaphragm Disuse in Humans Triggers Autophagy. American Journal of Respiratory and Critical Care Medicine, 2010, 182 (11), pp.1377 - 1386. 10.1164/rccm.201002-0234OC . hal-02546579

\section{HAL Id: hal-02546579 \\ https://hal.umontpellier.fr/hal-02546579}

Submitted on 18 Apr 2020

HAL is a multi-disciplinary open access archive for the deposit and dissemination of scientific research documents, whether they are published or not. The documents may come from teaching and research institutions in France or abroad, or from public or private research centers.
L'archive ouverte pluridisciplinaire HAL, est destinée au dépôt et à la diffusion de documents scientifiques de niveau recherche, publiés ou non, émanant des établissements d'enseignement et de recherche français ou étrangers, des laboratoires publics ou privés. 


\title{
Mechanical Ventilation-induced Diaphragm Disuse in Humans Triggers Autophagy
}

\author{
Sabah N. A. Hussain ${ }^{1,2}$, Mahroo Mofarrahi ${ }^{1,2}$, Ioanna Sigala ${ }^{3}$, Ho Cheol Kim ${ }^{4}$, Theodoros Vassilakopoulos ${ }^{3}$, \\ Francois Maltais ${ }^{5}$, Ion Bellenis ${ }^{6}$, Rakesh Chaturvedi ${ }^{2}$, Stewart B. Gottfried ${ }^{1,2}$, Peter Metrakos ${ }^{7,8}$, \\ Gawiyou Danialou ${ }^{1,9}$, Stefan Matecki ${ }^{10}$, Samir Jaber ${ }^{11}$, Basil J. Petrof ${ }^{1,2}$, and Peter Goldberg ${ }^{2}$ \\ ${ }^{1}$ Meakins Christie Laboratories, McGill University, Montréal, Québec, Canada; ${ }^{2}$ Critical Care and Respiratory Divisions, Royal Victoria Hospital, and \\ ${ }^{7}$ Transplant and Hepato-Pancreato-Biliary Research Group, McGill University Health Centre, Montréal, Québec, Canada; ${ }^{3}$ Department of Critical \\ Care and Pulmonary Services, University of Athens Medical School, Athens, Greece; ${ }^{4}$ Department of Internal Medicine, College of Medicine, \\ Gyeongsang Institute of Health Sciences, Gyeongsang National University, Jinju, Korea; ${ }^{5}$ Centre de recherche de I'Hôpital Laval, Institut universitaire \\ de cardiologie et de pneumologie, Université Laval, Québec, Québec, Canada; ${ }^{6}$ Department of Thoracic and Vascular Surgery, Evangelismos \\ Hospital, Athens, Greece; ${ }^{8}$ Department of Surgery, King Saud University, Riyadh, Kingdom of Saudia Arabia; ${ }^{9}$ Royal Military College Saint Jean, \\ Quebec, Canada; ${ }^{10}$ Service Central de Physiologie Clinique, INSERM, ERI 25 "Muscle et Pathologies", Hôpital Arnaud de Villeneuve, and \\ ${ }^{11}$ Department of Anesthesiology and Critical Care, Intensive Care Unit, Saint-Eloi Teaching Hospital, INSERM, ERI 25, Centre Hospitalier Universitaire \\ Montpellier, Montpellier, France
}

Rationale: Controlled mechanical ventilation (CMV) results in atrophy of the human diaphragm. The autophagy-lysosome pathway (ALP) contributes to skeletal muscle proteolysis, but its contribution to diaphragmatic protein degradation in mechanically ventilated patients is unknown.

Objectives: To evaluate the autophagy pathway responses to CMV in the diaphragm and limb muscles of humans and to identify the roles of FOXO transcription factors in these responses.

Methods: Muscle biopsies were obtained from nine control subjects and nine brain-dead organ donors. Subjects were mechanically ventilated for 2 to 4 hours and 15 to 276 hours, respectively. Activation of the ubiquitin-proteasome system was detected by measuring mRNA expressions of Atrogin-1, MURF1, and protein expressions of UBC2, UBC4, and the $\alpha$ subunits of the $20 \mathrm{~S}$ proteasome (MCP231). Activation of the ALP was detected by electron microscopy and by measuring the expressions of several autophagyrelated genes. Total carbonyl content and HNE-protein adduct formation were measured to assess oxidative stress. Total AKT, phosphorylated and total FOXO1, and FOXO3A protein levels were also measured.

Measurements and Main Results: Prolonged CMV triggered activation of the ALP as measured by the appearance of autophagosomes in the diaphragm and increased expressions of autophagy-related genes, as compared with controls. Induction of autophagy was associated with increased protein oxidation and enhanced expression of the FOXO1 gene, but not the FOXO3A gene. CMV also triggered the inhibition of both AKT expression and FOXO1 phosphorylation.

Conclusions: We propose that prolonged CMV causes diaphragm disuse, which, in turn, leads to activation of the ALP through oxidative stress and the induction of the FOXO1 transcription factor.

Keywords: proteasome; oxidative stress; FOXO proteins; AKT; skeletal muscles

Although mechanical ventilation is a life-saving procedure for patients with respiratory failure, there is increasing evidence

Supported by the Canadian Institute of Health Research, Research Institute of the MUHC and Transplant Quebec. M. Mofarrahi is the recipient of the Frederick Banting and Charles Best Canada Scholarship-Doctoral Award.

Correspondence and requests for reprints should be addressed to Sabah N. A. Hussain, M.D., Ph.D., Room L3.05, 687 Pine Avenue West, Montréal, Québec, Canada H3A 1A1. E-mail: sabah.hussain@muhc.mcgill.ca

\section{AT A GLANCE COMMENTARY}

Scientific Knowledge on the Subject

Diaphragm dysfunction has been described in animals and humans undergoing mechanical ventilation. The mechanisms of this dysfunction remain unknown.

\section{What This Study Adds to the Field}

We provide evidence that controlled mechanical ventilation in humans causes diaphragm disuse, which in turn activates both the autophagy and the proteasomal protein degradation pathways. We also provide evidence that these changes are triggered by oxidative stress and are mediated through activation of the FOXO1 transcription factor.

that prolonged rest-inactivity of the diaphragm induced by controlled mechanical ventilation (CMV) triggers disuse, which, in turn, elicits a condition known as ventilator-induced diaphragm dysfunction (1). In experimental animals, CMV, which allows no spontaneous diaphragm activity, is associated with significant reductions in diaphragm strength and endurance, muscle fiber atrophy and injury, fiber type remodeling, abnormal mitochondria, and alterations in the expressions of the transcription factors MyoD and myogenin (2-11). Little information is as yet available regarding the development of ventilator-induced diaphragm dysfunction in humans, although several authors have noted reductions in diaphragmatic contractile performance in patients who had undergone mechanical ventilation (MV) (12-14), and the development of significant diaphragm muscle atrophy has been confirmed in post mortem analyses of infants who had received ventilatory assistance for at least 12 days, immediately before death (15). More recently, however, Levine and colleagues (16) have provided the most compelling evidence of CMV-induced diaphragm disuse atrophy by using both microscopic and molecular analyses of diaphragmatic tissues to show substantial decreases in fiber cross-section, significant elevations of caspase- 3 and other degradation enzyme levels, and the development of oxidative stress.

$\mathrm{CMV}$-induced diaphragm disuse atrophy and the rapid loss of diaphragm muscle strength and endurance has been partly blamed on oxidative stress, which triggers both decreased protein synthesis and increased protein breakdown (17-21). Skeletal muscle protein degradation is accomplished via several distinct pathways, including the calpain, caspase-3, and the 
TABLE 1. DEMOGRAPHIC DATA, DURATION OF CONTROLLED MECHANICAL VENTILATION, REASON FOR SURGERY/CAUSE OF BRAIN DEATH, AND RELEVANT MEDICAL HISTORY FOR SUBJECTS WHO UNDERWENT DIAPHRAGM AND QUADRICEPS MUSCLE BIOPSIES

\begin{tabular}{|c|c|c|c|c|c|c|}
\hline Subject & Age $(y r)$ & Sex & $\mathrm{BMI}\left(\mathrm{kg} / \mathrm{m}^{2}\right)$ & CMV Duration (h) & Reason for Surgery/Cause of Brain Death & Relevant Medical History \\
\hline \multicolumn{7}{|c|}{ Diaphragm control group } \\
\hline 1 & 54 & M & 23.6 & & Lobectomy for lung cancer & Alcoholic, smoker \\
\hline 2 & 51 & $\mathrm{~F}$ & 22.7 & & Lobectomy for lung cancer & Hysterectomy \\
\hline 3 & 70 & $\mathrm{~F}$ & 29.3 & & Lobectomy for lung cancer & Hypertension, osteoporosis \\
\hline 4 & 56 & M & 24.0 & & Diaphragmatic hernia & Hypertension \\
\hline 5 & 59 & M & 30.1 & & Lobectomy for lung cancer & Hyperlipidemia, inguinal hernia \\
\hline 6 & 69 & M & 29.4 & & Segmentectomy for lung nodule & Hypertension, diabetes \\
\hline 7 & 66 & $\mathrm{~F}$ & 36.2 & & Lobectomy for lung cancer & Smoker \\
\hline 8 & 51 & $\mathrm{~F}$ & 25.0 & & Segmentectomy for lung nodule & Appendectomy, nephrolithiasis \\
\hline 9 & 67 & $\mathrm{~F}$ & 30.1 & & Lobectomy for lung cancer & Hypertension, hyperlipidemia \\
\hline \multicolumn{7}{|c|}{ Quadriceps control group } \\
\hline 1 & 72 & M & 28.3 & & & None \\
\hline 2 & 67 & M & 21.9 & & & Smoker \\
\hline 3 & 73 & M & 24.8 & & & Gluten-sensitive enteropathy \\
\hline 4 & 73 & M & 23.5 & & & None \\
\hline 5 & 64 & M & 28.2 & & & None \\
\hline 6 & 74 & M & 30.1 & & & None \\
\hline 7 & 73 & M & 29.8 & & & Hypertension \\
\hline 8 & 72 & M & 26.1 & & & Hypertension, Asthma \\
\hline 9 & 56 & M & 21.0 & & & Smoker \\
\hline 10 & 77 & M & 24.0 & & & None \\
\hline \multicolumn{7}{|c|}{ CMV group } \\
\hline 1 & 65 & M & 28.5 & 32.5 & Cerebrovascular accident & Angina, smoker, depression \\
\hline 2 & 75 & M & 24.8 & 29 & Cerebrovascular accident & $C A D$, hyperlipidemia \\
\hline 3 & 32 & M & 28.4 & 34 & Cerebrovascular accident & Marijuana smoker \\
\hline 4 & 64 & M & 32.4 & 36 & Cerebrovascular accident & Hyperlipidemia, hemorrhoids \\
\hline 5 & 55 & M & 27.4 & 42 & Cerebrovascular accident & Smoker \\
\hline 6 & 27 & $\mathrm{~F}$ & 30.7 & 176 & Pulmonary embolism & Tonsillectomy \\
\hline 7 & 60 & $\mathrm{~F}$ & 25 & 66 & Cerebrovascular accident & Osteoporosis, depression \\
\hline 8 & 44 & $\mathrm{~F}$ & 43.7 & 93 & Cerebrovascular accident & $\mathrm{N} / \mathrm{A}$ \\
\hline 9 & 72 & $\mathrm{~F}$ & 22.9 & 15 & Cerebrovascular accident & Chest nodule, smoker \\
\hline
\end{tabular}

Definition of abbreviations: $\mathrm{BMI}=$ body mass index; $\mathrm{CMV}=$ controlled mechanical ventilation; $\mathrm{F}=$ female; $\mathrm{M}=$ male.

ubiquitin-proteasome system (UPS), which are responsible for the degradation of cytosolic, nuclear, and myofibrillar proteins (22). Levine and colleagues (16) have recently shown that CMV-induced diaphragm disuse in humans triggers enhanced capase-3 activity and up-regulation of two muscle-specific E3 ligases, FBXO32 (Atrogin-1) and TRIM63 (MURF1). Atrogin1 is a muscle-specific F-box protein and MURF1 is one of a specific class of RING finger proteins.

The autophagy-lysosome pathway (ALP) is a fourth protein degradation pathway that is involved in skeletal muscle breakdown. Autophagy is a self-degradative process that is involved in basal turnover of cellular components in addition to being responsible for removing damaged cellular components in response to nutrient starvation or injury (23). During autophagy, portions of the cytoplasm, or whole organelles such as mitochondria, are sequestered by double-membraned vesicles called autophagosomes. Autophagosome formation is a multistep process controlled by a set of factors termed autophagyrelated genes (ATG). In limb muscles, autophagy is constitutively active and is strongly induced during fasting, oxidative stress, and denervation, resulting in significant muscle protein degradation (24-27). However, the contribution of autophagy to proteolysis in the diaphragm has never been investigated. The first objective of this study, therefore, is to test the hypothesis that, in human diaphragms exposed to prolonged CMV, the ALP is induced in tandem with the UPS.

The ALP and UPS are controlled by protein kinase B (AKT) and FOXO transcription factors. FOXO proteins are targeted for phosphorylation by AKT at specific sites (FOXO1 at $\mathrm{Ser}^{256}$, FOXO3A at $\mathrm{Ser}^{253}$, which results in their binding to 14-3-3 proteins in the cytosol, which leads to subsequent reductions in transcriptional activity. Inhibition of AKT-mediated phosphorylation, in contrast, mobilizes FOXO factors to the nucleus where they induce the expression of Atrogin-1 and MURF1 and several autophagy-related genes $(25,26,28)$. The involvement of FOXO transcription factor in the regulation of the ALP has never been investigated in the mechanically ventilated diaphragm. The second objective of this study, therefore, is to test the hypothesis that, in human diaphragms exposed to prolonged CMV, the ALP is significantly induced and that this induction is associated with the activation of FOXO transcription factors.

\section{METHODS}

\section{Experimental Subjects}

All protocols were approved by the appropriate ethics committees of McGill University, University of Athens, and Laval University. All

TABLE 2. SUMMARY OF VENTILATOR SETTINGS, ARTERIAL BLOOD GASES, AND VITAL SIGNS FOR THE CONTROLLED MECHANICAL VENTILATION AND CONTROL GROUPS

\begin{tabular}{lcc}
\hline Ventilator Settings & $\begin{array}{c}\text { Control Group } \\
(n=9)\end{array}$ & $\begin{array}{c}\text { CMV Group } \\
(n=9)\end{array}$ \\
\hline Tidal volume, $\mathrm{ml} / \mathrm{kg}$ & $7.1 \pm 0.9$ & $7.8 \pm 1.9$ \\
Ventilation frequency, breaths/min & $14.5 \pm 1.5$ & $15.6 \pm 1.2$ \\
$\mathrm{PEEP}, \mathrm{cm} \mathrm{H} \mathrm{H}_{2} \mathrm{O}$ & 5 & 5 \\
$\mathrm{Sa}_{\mathrm{O}_{2^{\prime}} \%}$ & $98.5 \pm 0.5$ & $99.3 \pm 0.3$ \\
$\mathrm{pH}$ & - & $7.41 \pm 0.01$ \\
$\mathrm{~Pa}_{\mathrm{O}_{2^{\prime}} \mathrm{mm} \mathrm{Hg}}$ & - & $260.7 \pm 52.9$ \\
$\mathrm{~Pa}_{\mathrm{CO}_{2^{\prime}} \mathrm{mm} \mathrm{Hg}}$ & - & $37 \pm 1.8$ \\
$\mathrm{Vital}_{\text {Signs }}$ & $112 \pm 9$ & $109 \pm 7$ \\
$\quad$ Systolic pressure, $\mathrm{mm} \mathrm{Hg}$ & $70 \pm 11$ & $3.7 \pm 4.3$ \\
Diastolic pressure, $\mathrm{mm} \mathrm{Hg}$ & $73 \pm 5$ & $96 \pm 8^{*}$ \\
Heart rate, beats/min &
\end{tabular}

Values are means \pm SEM. ${ }^{*} P<0.05$, compared with control group. 

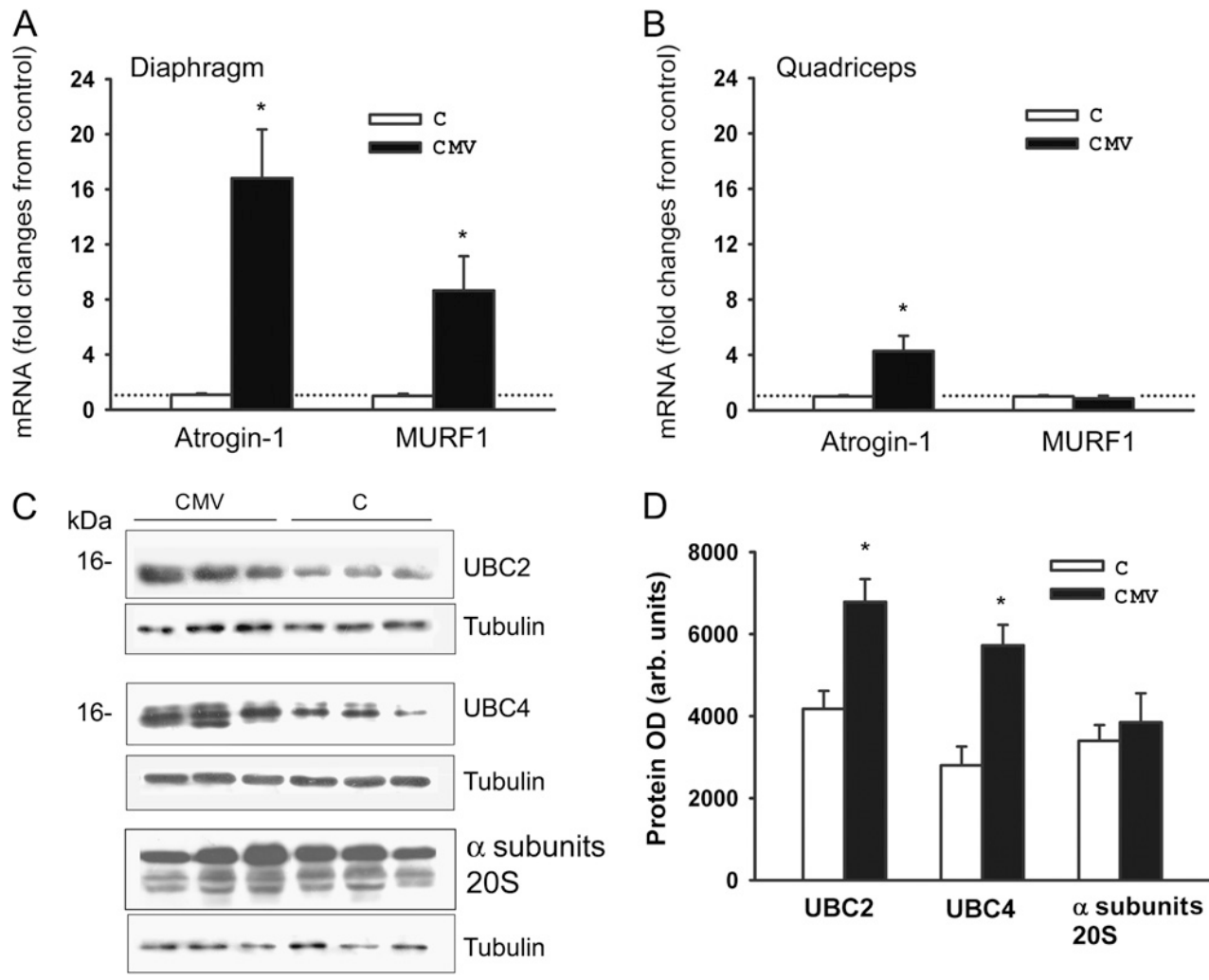

Figure 1. (A) Changes in mRNA expression levels of Atrogin-1 and MURF1 in the diaphragms of control subjects (C) and subjects undergoing controlled mechanical ventilation $(\mathrm{CMV}) .{ }^{*} P<0.05$ compared with control subjects. (B) Changes in mRNA expression levels of Atrogin-1 and MURF1 in the quadriceps muscles of control subjects and subjects undergoing CMV. ${ }^{*} P<0.05$ compared with control subjects. (C) Representative

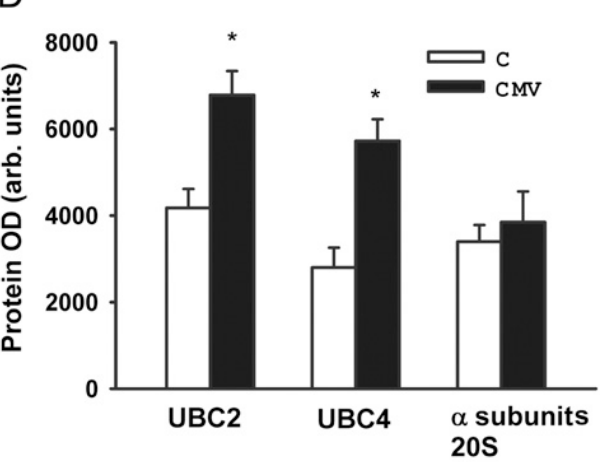
immunoblots of UBC2, UBC4, and a subunits of the $20 \mathrm{~S}$ proteasome in diaphragms of the $\mathrm{C}$ and the CMV groups. $(D)$ Mean values of protein optical densities (OD) of UBC2, UBC4, and $\alpha$ subunits of the $20 S$ proteasome in diaphragms of the $C$ and CMV groups. ${ }^{*} P<0.05$ compared with control subjects.

biopsies were obtained with appropriate written informed consent. Full-thickness diaphragm biopsies were obtained from nine control subjects with normal pulmonary function who had undergone thoracotomy due to localized lung neoplasms or to repair diaphragmatic herniae (diaphragm control group). A second group of 10 sedentary subjects with normal pulmonary function underwent needle biopsies of the quadriceps muscle (quadriceps control group), performed at midthigh, as described by Bergstrom (29). Subjects with chronic respiratory failure, coronary artery disease, neuromuscular disease, chronic metabolic disease, and/or treatment with drugs known to alter muscle structure and function were excluded. The CMV group consisted of nine brain-dead organ donors who had been subjected to prolonged CMV. Tissue samples were obtained before circulatory arrest or removal of any organ. Full-thickness biopsies were obtained from the anterior costal diaphragm, lateral to the insertion of the phrenic nerve. Quadriceps muscle samples were obtained from the midthigh region. All biopsy samples were immediately frozen in liquid nitrogen and stored at $-80^{\circ} \mathrm{C}$.

\section{RNA Extraction}

Total RNA was extracted from human muscle samples using a commercial kit and mRNA expressions of Atrogin-1, MURF1, autophagyrelated proteins, FOXO1, and FOXO3A were measured with real-time polymerase chain reaction and appropriate primers, as previously described (30).

\section{Immunoblotting}

Samples were loaded onto tris-glycine sodium dodecyl sulfate-polyacrylamide gel electrophoresis. Proteins were electrophoretically transferred onto polyvinylidene difluoride membranes, blocked with nonfat dry milk, and then incubated overnight with primary antibodies to the ubiquitin-conjugating enzymes UBE2B (UBC2) and UBE2D2 (UBC4), the $\alpha$ subunits of the 20S proteasome (MCP231), BECN1, LC3, ATG5, ATG7, 4-hydroxy-2-nonenal (HNE)-protein adducts, 3nitrotyrosine, AKT, phospho-FOXO1 $\left(\mathrm{Ser}^{256}\right)$, FOXO1, phosphoFOXO3A (Ser $\left.{ }^{253}\right)$, FOXO3A, and tubulin. Proteins were detected using a commercial kit and optical densitometry, as previously described (30).

\section{Detection of Oxidative and Nitrosative Stress}

To evaluate the effects of CMV on the development of oxidative stress/ protein oxidation, protein carbonylation, HNE-protein adduct formation, and tyrosine nitration were measured using a commercial kit and optical densitometry, as previously described (31).

\section{Statistical Analysis}

Results are expressed as means \pm SE in all figures. A two-way analysis of variance followed by a Tukey test was used to compare differences in the expressions of the E3 ligases Atrogin-1 and MURF1, the E2 ubiquitin conjugases UBC2 and UBC4, the $\alpha$ subunits of the $20 \mathrm{~S}$ proteasome, all autophagy-related proteins, total AKT, FOXO1, and FOXO3A, and phosphorylated FOXO1 and FOXO3A. Protein oxidation and nitration values were also compared this way. Pearson correlation coefficient was used to assess relationships between Atrogin-1 and MURF1 and autophagy-related gene expressions in relation to CMV duration. A Bonferroni-type adjustment was performed to address the effects of doing multiple comparisons and correlations (32). $P$ values less than $5 \%$ were considered significant. Statistical analyses were performed with SigmaStat software (Jandel Scientific, Chicago, IL).

For detailed descriptions of all experimental methods, materials, and models, see the online supplement.

\section{RESULTS}

Demographic data, duration of CMV, reason for surgery or cause of brain death, relevant medical histories, ventilator settings, arterial blood gases, vital signs, and clinical data for the diaphragm control and CMV groups are listed in Tables 1 and 2, and Table E2 in the online supplement. Characteristics of the subjects enrolled in the quadriceps control group are listed in Table 1 and Table E3. No differences in age (60.3 \pm 2.6 vs. $54.9 \pm 5.7 \mathrm{yr})$ or body mass index $(27.8 \pm 1.5$ vs. $28.8 \pm$ $2.0 \mathrm{~kg} / \mathrm{m}^{2}$ ) existed between the diaphragm control group and the CMV group (Table 1). The diaphragm control group consisted of five women and four men, whereas the CMV group consisted of four women and five men. The duration of mechanical 
A
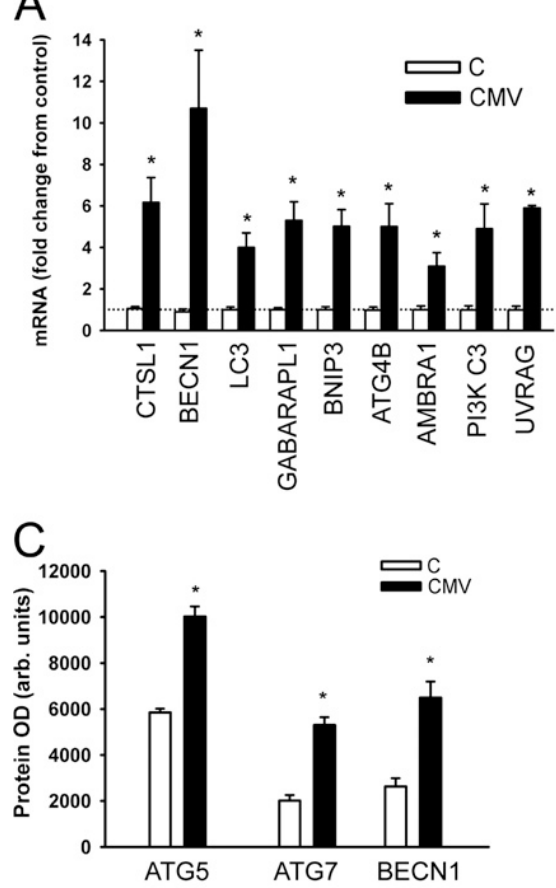

E

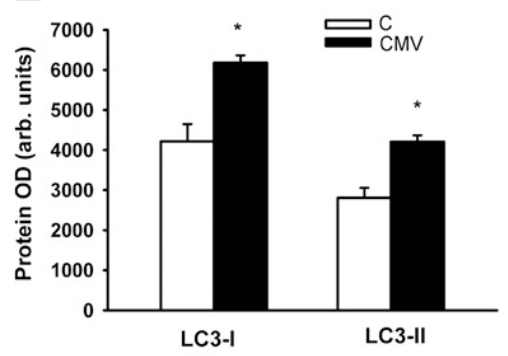

$\mathrm{B}$

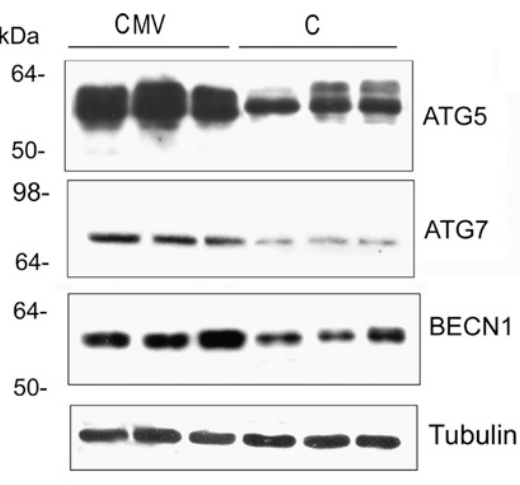

D

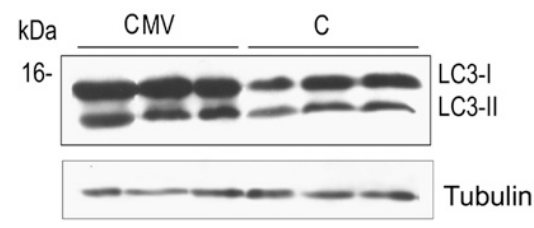

F

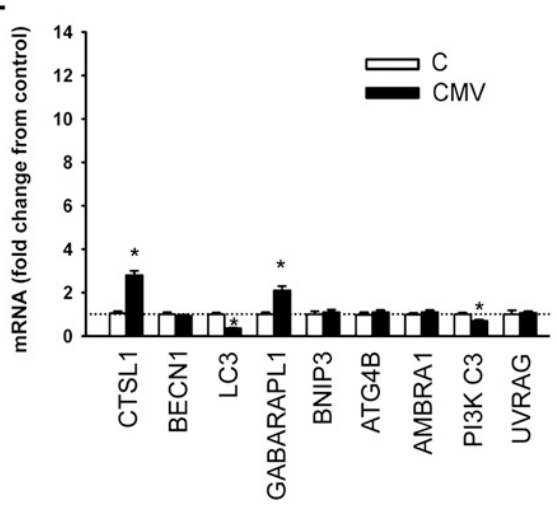

Figure 2. (A) Relative changes in mRNA expression levels of various autophagy-related genes in diaphragms of the control (C) and controlled mechanical ventilation (CMV) groups. (B) Representative immunoblots of BECN1, ATG5, and ATG7 in diaphragms of the $C$ and CMV groups. (C) Mean values of protein optical densities (OD) of BECN1, ATG5, and ATG7 in diaphragms of the $C$ and $C M V$ groups. ${ }^{*} P<0.05$ compared with control subjects. $(D)$ Representative immunoblots of LC3-I and LC3-II in diaphragms of the C and CMV groups. (E) Mean values of protein optical densities of LC3-I and LC3-II in diaphragms of the $C$ and $C M V$ groups. ${ }^{*} P<0.05$ compared with control subjects. $(F)$ Relative changes in mRNA expression levels of various autophagy-related genes in quadriceps muscles of the $\mathrm{C}$ and CMV groups. Symbols are as in Figure 1A. ventilation in the diaphragm control group was between 2 and 4 hours. In contrast, in the CMV group, CMV was maintained for $59.0 \pm 16.5$ hours $(P<0.05$ as compared with the control group). The heart rate was the only vital sign that was significantly higher in the CMV group compared with the control group (Table 2).

Figure 1 summarizes changes in expressions of the E3 ligases Atrogin-1 and MURF1, the E2 ubiquitin conjugases UBC2 and UBC4, and the $\alpha$ subunits of the 20S proteasome in the diaphragms of the control and the CMV groups. Atrogin-1 and MURF1 mRNA levels were higher by more than 16- and 8fold, respectively, in the diaphragms of the CMV group, as compared with the diaphragm control group (Figure 1A). Diaphragm selectivity to the induction of Atrogin-1 and MURF1 was assessed by comparing their expressions in quadriceps muscles of the CMV group to quadriceps muscles of the quadriceps control group. Atrogin-1 mRNA was elevated approximately fourfold in the CMV group as compared with the quadriceps control samples, whereas MURF1 expression was similar between the two groups (Figure 1B). These results suggest that CMV elicits substantially stronger induction of Atrogin-1 expression in the diaphragm than it does in limb muscles and that it selectively induces MURF1 in the diaphragm.
Expressions of two important E2 conjugases (UBC2 and UBC4) and $\alpha$ subunits of the 20S proteasome were also assessed in the diaphragm in response to CMV. Both conjugases and $\alpha 1$, $\alpha 2, \alpha 3, \alpha 5, \alpha 6$, and $\alpha 7$ subunits were detected by immunoblotting in the control and CMV groups (Figure 1C). No differences in the intensities of $\alpha$ subunit bands were observed between the groups. UBC2 and UBC4 protein levels were significantly higher in the diaphragms of the CMV group, as compared with those of the control group, indicating that CMV elicits significant induction of these E2 conjugases (Figure 1D).

In the diaphragm, CMV elicited significant induction of mRNA levels of the autophagy-related proteins CTSL1, BECN1, LC3, GABARAPL1, BNIP3, ATG4B, AMBRA1, PI3K C3, and UVRAG (Figure 2A). Similarly, CMV elicited significant increases in protein levels of BECN1, ATG5, and ATG7 (Figures 2B and 2C). Activation of autophagy in the CMV group was confirmed by performing immunoblotting for LC3, a mammalian homolog of yeast ATG8. During autophagic vacuole formation, LC3 is cleaved and conjugated to phosphatidylethanolamine to generate a fast-migrating form, LC3-II (33). In the CMV group, increases in the levels of both cytosolic LC3-I and membrane-bound LC3-II protein bands were observed, suggesting increased conjugation of LC3 to phosphatidylethanolamine (Figures 2D and 2E). However, it should be 

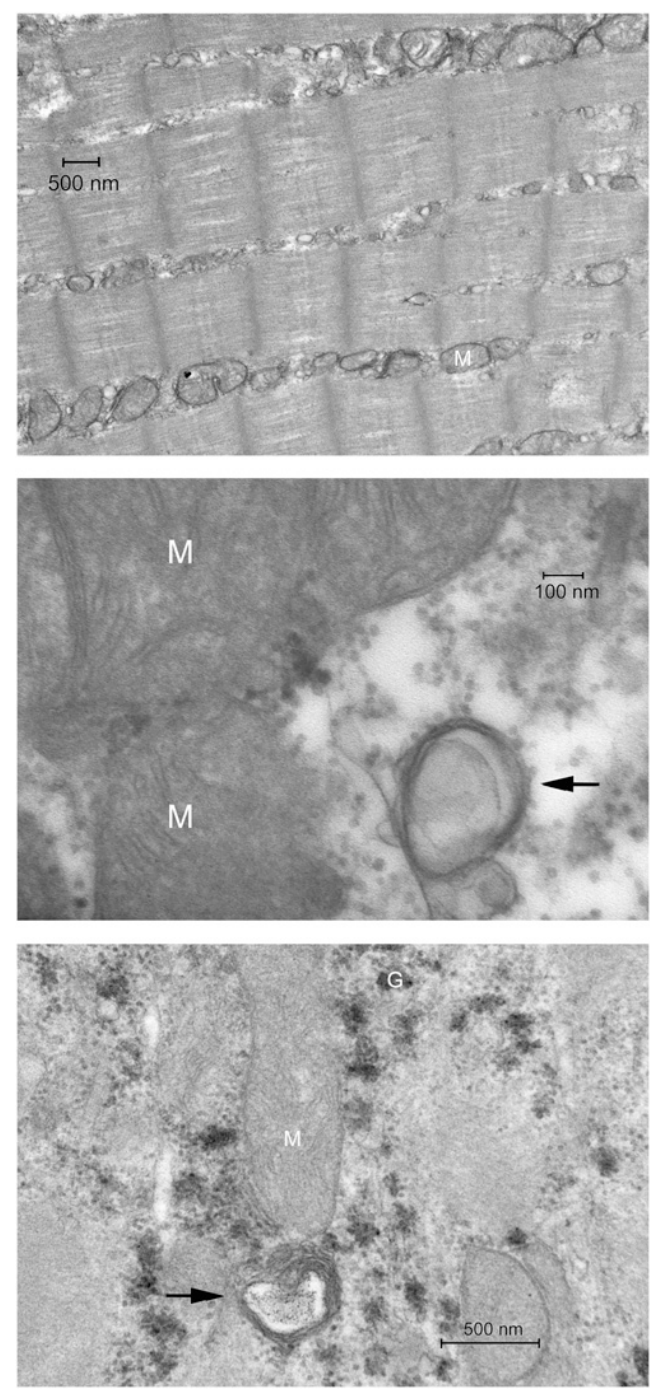

Figure 3. (Upper panel) Representative electron micrograph of a section of a diaphragm from a control subject showing normal ultrastructure and absence of autophagosomes. (Middle and bottom panels) Representative electron micrographs of a section of a diaphragm from a brain-dead organ donor undergoing controlled mechanical ventilation. These sections show autophagosomes (black arrows) in close proximity to mitochondria $(M) . G$ indicates glycogen particles.

emphasized that the localization of LC3 to the autophagosome in the diaphragms of both groups of subjects was not monitored. In contrast to the significant increases in autophagy-related gene expressions that were observed in CMV group diaphragms, in the quadriceps muscles MV elicited only minor changes in mRNA levels of CTSL1 and GABARAPL1, and expressions of LC3 and PI3K C3 actually declined in these samples as compared with the control group (Figure $2 \mathrm{~F}$ ). Expressions of all other autophagy-related genes in the quadriceps showed no significant differences between the CMV and control groups (Figure 2F).

To confirm that autophagy was induced in the diaphragms of the CMV group, muscle fiber ultrastructure was analyzed using electron microscopy. One marker of autophagy is the presence of double-membraned autophagosome vesicles in close proximity to the mitochondria. These were observed in the diaphragms of the CMV group, but not in the control group (Figure 3).

Regression analysis using individual autophagy-related genes and the duration of CMV revealed positive and significant correlations between CTSL1 and BECN1 mRNA levels and duration, although no such relationships were detected for the remaining autophagy-related genes (Figure 4A). Positive and significant correlations between relative changes in expressions of all autophagy-related genes, except BECN1, and expressions of MURF1 and Atrogin-1 were also observed (Figure 4B).

To assess the influence of CMV on protein oxidation (an index of oxidative stress), total carbonyl content and HNEprotein adduct formation were measured in the diaphragm using immunoblotting. In control and CMV samples, 7 protein bands were strongly carbonylated (Figure 5A) and 12 positive bands were detected by the anti-HNE-protein adduct antibody (Figure 5B). Intensities of total protein carbonyl content and HNE-protein adducts were significantly higher in the CMV group as compared with the control group (Figure 5C), suggesting that $\mathrm{CMV}$ elicits increased protein oxidation in the diaphragm. Immunoblots of 3-nitrotyrosine formation (an index of nitrosative stress) revealed no significant changes in total muscle 3-nitrotyrosine formation in the diaphragms of either the control or CMV groups (Figure 5C).

Previous studies have revealed that in skeletal muscle fibers undergoing denervation or fasting, FOXO transcription factors are important regulators of Atrogin-1, MURF1, and autophagyrelated genes $(25,26,28)$. When phosphorylated by AKT, these factors are inactivated and localized within the cytosol. Measurements of total AKT protein levels revealed significantly lower levels in the diaphragms of the CMV group compared with the control group (Figure 6A). Total FOXO1 mRNA (Figure 6B) and protein levels (Figures $6 \mathrm{C}$ and $6 \mathrm{E}$ ) in the diaphragm were significantly higher in the CMV group, whereas phosphorylation intensity of FOXO1 at $\mathrm{Ser}^{256}$ was lower in the CMV group compared with the control group (Figure 6E). mRNA and protein expression levels of FOXO3A were unchanged in the CMV group, as was phosphorylation intensity of FOXO3A at $\mathrm{Ser}^{253}$, compared with the control group (Figures 6D and 6E).

\section{DISCUSSION}

In this study, we investigated the relationship between prolonged MV and autophagy in the diaphragm. Our results indicate that $\mathrm{CMV}$ is associated with the following changes: (1) Significant up-regulation of Atrogin-1, MURF1, UBC2, and UBC4; (2) Significant induction of several autophagy-related genes and morphological evidence of autophagosome formation; (3) Significant increases in protein carbonyl content and HNE-protein adduct formation; (4) Significant decreases in total AKT protein levels coincident with up-regulation of FOXO1 mRNA and protein levels and decreased FOXO1 phosphorylation.

\section{Limitations of the Study}

One limitation of the study is that neither diaphragm contractility nor fiber atrophy was measured. This is due to difficulties in obtaining diaphragm samples of sufficient size from the control groups. There is, however, ample evidence in experimental animals that the use of CMV for periods as short as 18 hours elicits significant decreases in diaphragm contractility and results in atrophy of type I and type II fibers in both humans and experimental animals $(11,16,18)$. On the basis of these findings, we assume that the prolonged CMV that was experienced by the CMV group subjects likely resulted in decreased contractile performance and muscle fiber atrophy.

Another limitation of the study is that we have no direct evidence that ALP and UPS induction in the CMV group is due solely to the effects of CMV-induced diaphragm disuse. It could be argued that factors other than diaphragm disuse might have 

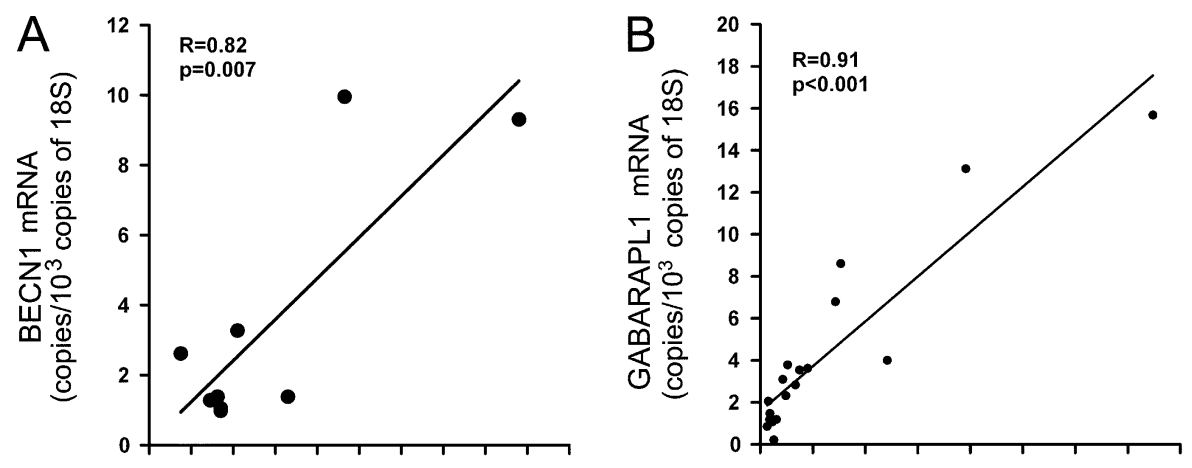

Figure 4. $(A)$ Linear correlations between the duration of mechanical ventilation and mRNA expression levels of BECN1 (top) and CTSL1
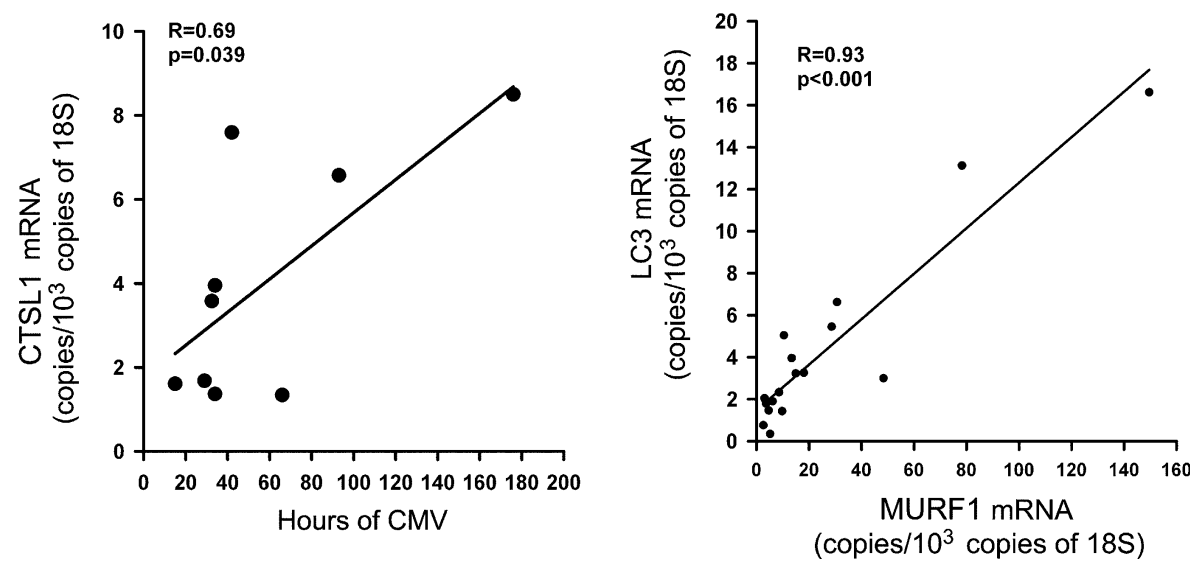
(bottom) in the diaphragms of the controlled mechanical ventilation (CMV) group. (B) Linear correlations between mRNA expression levels of MURF1 and GABARAPL1 (top) and LC3 (bottom) in the diaphragms of the CMV group.

caused up-regulation of these proteolytic pathways in the diaphragm. These factors might include hormonal and cytokine disorders associated with brain death and nutrition-related biochemical abnormalities $(34,35)$. However, we believe that these factors were not important because in the quadriceps muscle samples of the CMV group, only mild induction of Atrogin-1 was observed, yet no changes in the expressions of MURF1 were observed, nor were they for the majority of autophagy-related genes.

\section{Activation of Muscle Proteolysis by CMV}

Many studies with experimental animals have confirmed that MV-induced diaphragm disuse activates the calpain, caspase-3, and UPS proteolytic pathways $(18,20,36,37)$. Levine and
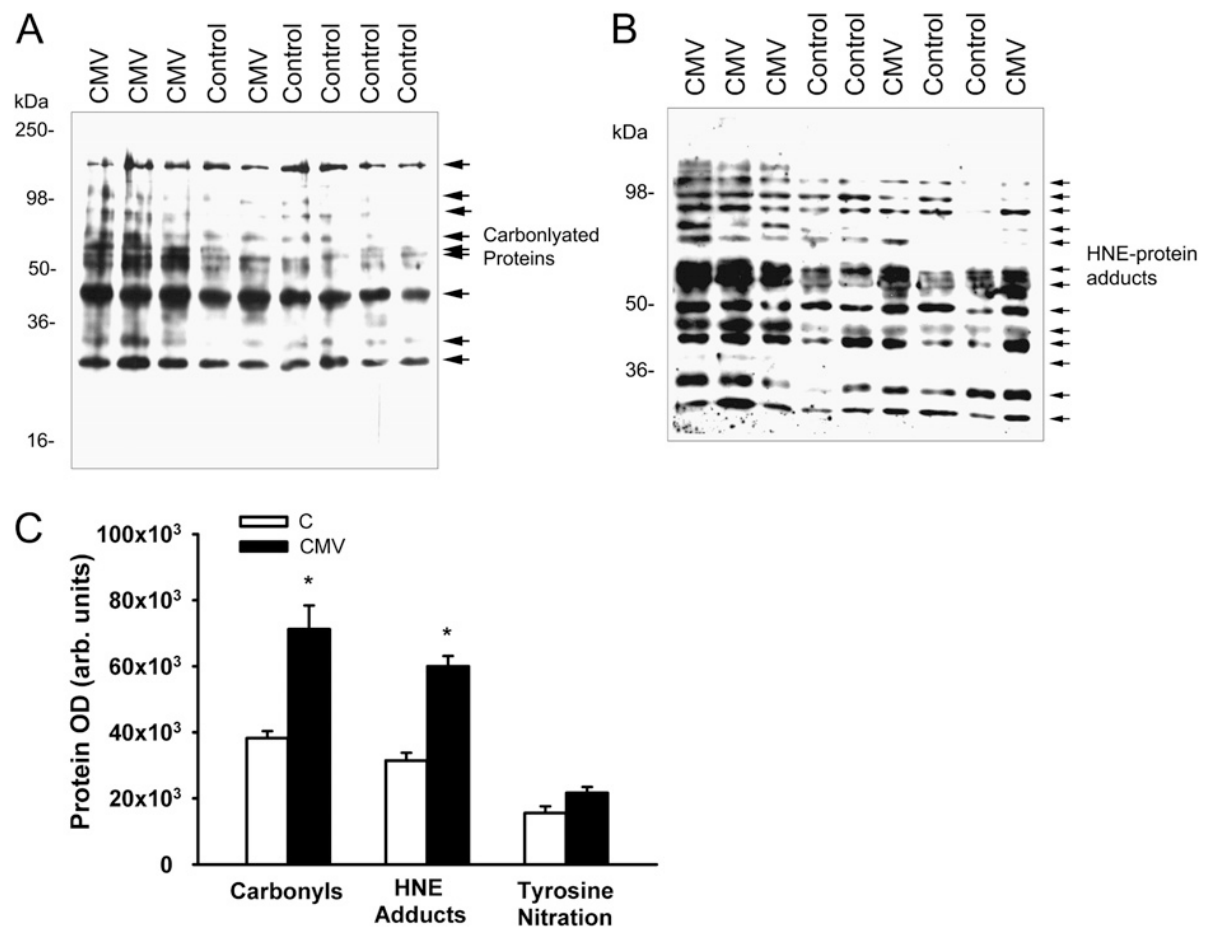

Figure 5. (A) Representative immunoblots of carbonylated proteins in diaphragms of the control (C) and controlled mechanical ventilation (CMV) groups. (B) Representative immunoblots of 4-hydroxy-2-nonenal (HNE)-protein adducts in diaphragms of the $\mathrm{C}$ and $\mathrm{CMV}$ groups. (C) Mean values of protein optical densities (OD) of carbonylated proteins, HNEprotein adducts, and tyrosine-nitrated proteins in diaphragms of the $C$ and $C M V$ groups. ${ }^{*} P<$ 0.05 compared with control subjects. 
A

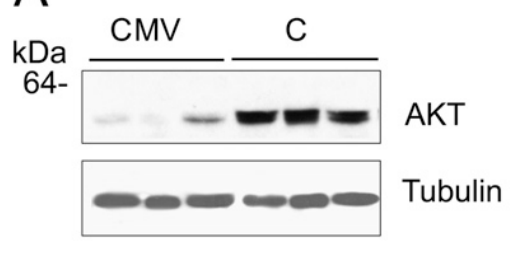

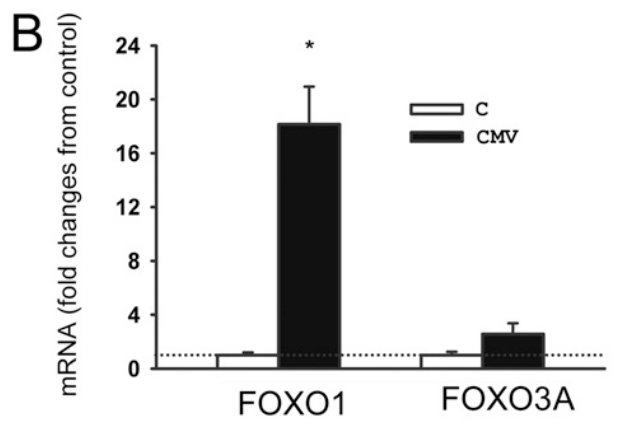

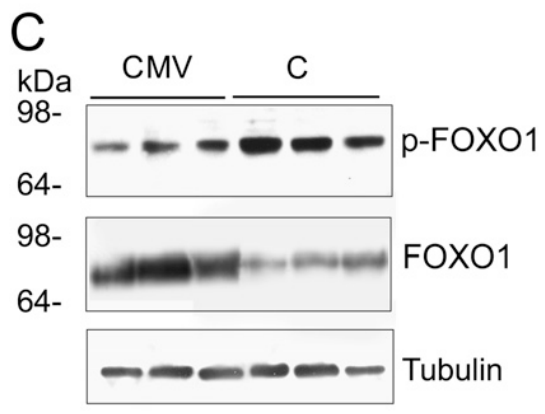

D

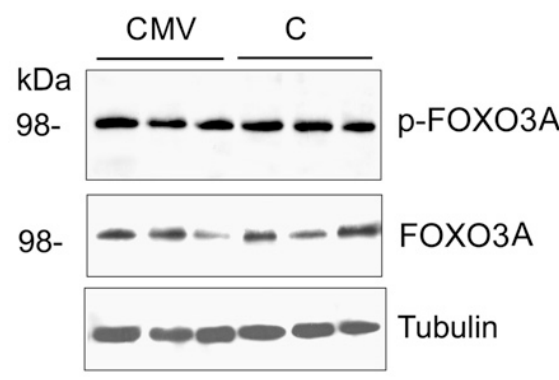

Figure 6. (A) Representative immunoblot of total AKT in diaphragms of the control (C) and controlled mechanical ventilation (CMV) groups. ${ }^{*} P<0.05$ compared with control subjects. (B) Mean values of mRNA expression fold change of FOXO1 and FOXO3A in diaphragms of the $\mathrm{C}$ and $\mathrm{CMV}$ groups. (C) Representative immunoblots of phospho-FOXO1 (ser ${ }^{256}$ ) and FOXO1 in diaphragms of the $\mathrm{C}$ and $\mathrm{CMV}$ groups. (D) Representative immunoblots of phospho-FOXO3 $\left(\mathrm{ser}^{253}\right.$ ) and FOXO3A in diaphragms of the $C$ and $C M V$ groups. (E) Mean values of protein optical densities (OD) of total AKT, total FOXO1, phospho-FOXO1 $\left(\operatorname{ser}^{256}\right)$, total FOXO3A, and phospho-FOXO3A ( $\operatorname{ser}^{253}$ ) in diaphragms of the $\mathrm{C}$ and $\mathrm{CMV}$ groups.
E

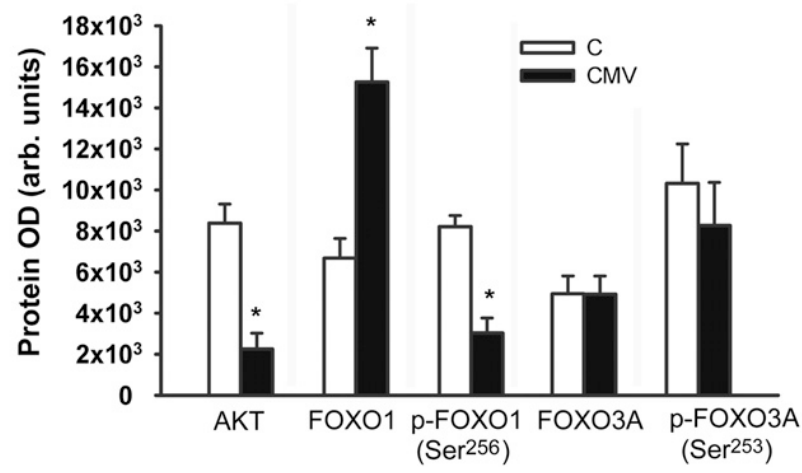

colleagues (16) provided the first evidence of enhanced capase-3 activation and induction of Atrogin-1 and MURF1 in the diaphragms of mechanically ventilated brain-dead organ donors. Our findings of induction of Atrogin-1 and MURF1 mRNA levels in the diaphragms of the CMV group are in accordance with those of Levine and colleagues (16). We also report here that CMV exerted no influence on the expression of the $\alpha$ subunits of the $20 \mathrm{~S}$ proteasome, although it significantly induced the ubiquitin conjugases (E2) UBC2 and UBC4. These results are similar to previous in vivo and in vitro studies, which confirmed that E2 conjugases are induced in conditions where muscle atrophy develops, such as fasting, $\mathrm{H}_{2} \mathrm{O}_{2}$ exposure, and sepsis (38-40).

\section{Activation of the ALP}

Although basal autophagy is important for maintaining cell survival by recycling old and damaged organelles and cytosolic proteins, excessive autophagy, beyond a certain threshold, induces pathological changes, such as apoptosis, or cell death, and, in the case of skeletal muscle, significant atrophy. Several studies have described the induction of autophagy-related genes and the lysosomal CTSL1 in murine limb muscles in response to fasting, denervation, oxidative stress, sepsis, and dexamethasone administration $(25-27,41)$. However, to our knowledge, the induction of autophagy in response to atrophy-inducing conditions has never been documented in the diaphragm. We report here, for the first time, that $\mathrm{CMV}$-induced diaphragm disuse in humans triggers the appearance of double-membraned autophagosomes in diaphragm muscle fibers and that this is coincident with significant induction of autophagy-related genes that are involved in the initiation, elongation, and maturation of the autophagosomes (Figure 2).

Another important observation is that CMV triggers simultaneous induction of the ALP and UPS in the diaphragm and that relative changes in E3 ligase (Atrogin-1 and MURF1) expressions correlate positively with those of autophagy genes. This observation suggests that the ALP and UPS are regulated by common mechanisms. One such potential mechanism is oxidative stress, which was evident in the diaphragms of subjects undergoing CMV and manifested as significant increases in total carbonyls and HNE-protein adduct formation (Figure 5). The association between oxidative stress and E3 ligase induction has been confirmed in both the diaphragm and limb muscles in experimental animals and, more recently, by Levine and colleagues in humans undergoing MV (16, 18, 42-44). Similarly, a recent study (27) has confirmed that autophagy is substantially induced in limb muscles on selective overexpression of a mutant form of $\mathrm{Mn}-\mathrm{SOD}$, which triggers severe oxidative stress in these muscles.

The induction of the ALP and UPS by oxidative stress is mediated mainly through the AKT/FOXO transcription factor pathway in which AKT is activated by the PI3-kinase pathway and the mammalian target of rapamycin (mTOR)-2 complex in response to growth-promoting stimuli, such as insulin-like growth factor 1 (IGF-1) or insulin. Activation of AKT promotes protein synthesis inside skeletal muscles by activating the mTOR1 complex and by inhibiting glycogen synthase kinase 


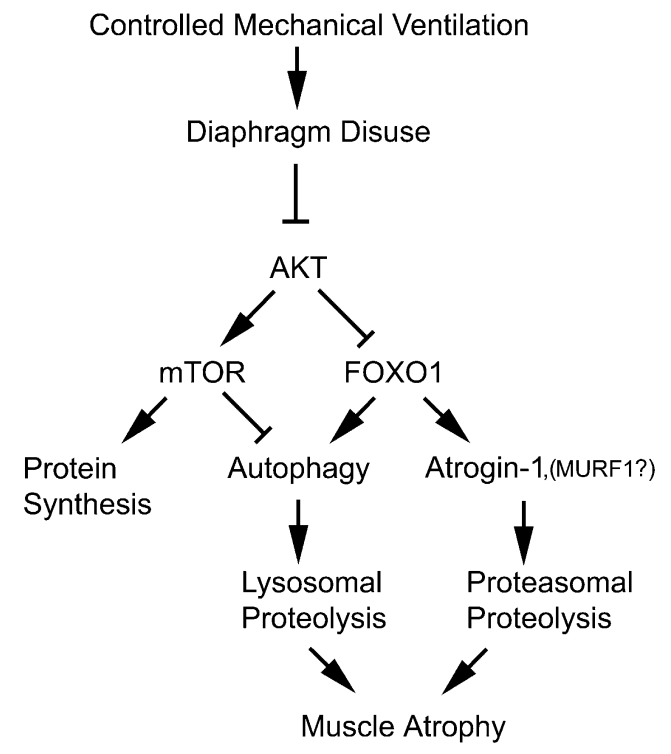

Figure 7. Schematic depiction of proposed signaling pathways through CMV elicits induction of autophagy and the proteasomal pathways in diaphragm muscle fibers.

$3 \beta$ (GSK3 $\beta$ ) (45). At the same time it inhibits proteolysis through phosphorylation and inhibition of the FOXO transcription factors (FOXO1, FOXO3A, and FOXO4) (46). Contrarily, inhibition of the AKT pathway results in decreased protein synthesis and activation of the FOXO transcription factors, which then mobilize to the nucleus and bind to the promoters of Atrogin-1, MURF1, and several other autophagy-related genes, leading to the development of skeletal muscle atrophy.

In cultured skeletal myotubes, deprivation of nutrients causes attenuation of AKT phosphorylation with no change in AKT levels (28). In contrast, limb muscle atrophy elicited by disuse or chronic hypoxia is associated with significant reductions in AKT transcription $(47,48)$. We observed that CMV-induced diaphragm disuse also results in significant reductions in total AKT protein levels in the diaphragm, indicating that the AKT pathway is inhibited as a consequence of down-regulation of AKT expression. Mechanisms behind this remain to be investigated.

Many reports have confirmed the involvement of FOXO1 and FOXO3A proteins in the regulation of Atrogin-1 and MURF1 (28, 49-51). Recently, a critical role for FOXO3A was discovered in murine limb muscles experiencing starvationand denervation-induced autophagy $(25,26)$. AKT-mediated phosphorylation regulates muscle FOXO DNA activity, as do changes in total FOXO protein levels. For instance, in nutrientstarved skeletal myotubes, significant inductions of FOXO1, FOXO3A, and FOXO4 proteins have been documented (28). Lecker and colleagues (52) have reported that FOXO1 gene expression is substantially induced in atrophied muscles of fasted mice, rats with cancer cachexia, streptozotocin-induced diabetes mellitus, and uremia. In the rat diaphragm, McClung and colleagues (53) have reported that MV is associated with dephosphorylation, increased nuclear protein abundance of FOXO1, and decreased nuclear abundance of FOXO3A. We report here that CMV triggers both dephosphorylation and induction of FOXO1 transcription in the diaphragms of the CMV group, whereas FOXO3A phosphorylation intensity and total protein levels do not significantly change, as compared with the control group. These results suggest that FOXO1, rather than FOXO3A, is preferentially activated in response to $\mathrm{CMV}$-induced disuse atrophy in human diaphragms.
In addition to its well-known role in the regulation of Atrogin-1 and MURF1 (54), FOXO1 might also be an important element in the induction of autophagy in the diaphragms of patients undergoing CMV. This supposition is based on the relatively high degree of homology between the FOXO DNAbinding domains of FOXO1 and FOXO3A, such that FOXO1 has marked affinity for a number of FOXO3A-binding elements that have been identified in the promoters of several autophagyrelated genes and lysosomal cathepsins $(54,55)$.

\section{Implications}

We propose, on the basis of our results and those previously described in limb muscles (26), that prolonged CMV with its accompanying diaphragm disuse causes significant inhibition of AKT (Figure 7). It is tempting to speculate that this reduction of AKT inside muscle fibers attenuates mTORC1 complex activity, thereby inhibiting protein synthesis. Attenuation of mTORC1 complex activity would also induce autophagy because one of the roles of the complex is to phosphorylate ATG13 and to inactivate the ATG1 complex, which is a critical initiator of autophagosome formation (56). Inhibition of AKT likely stimulates the ALP and UPS pathways through activation of FOXO1, which binds to the promoters of Atrogin-1, MURF1, and several autophagy-related genes as a trigger for the transcription process (Figure 7). This, in turn, stimulates activation of the ALP and UPS and triggers the development of skeletal muscle atrophy $(25,26,28)$.

In atrophying muscles, autophagy, controlled by the ALP, is the primary mechanism for removing damaged organelles, such as mitochondria. Protein degradation, controlled by the UPS, is responsible for breaking down myofibrils. Simultaneous activation of the ALP and UPS in CMV-disused diaphragmatic tissue presumably leaves the mitochondrial to myofibrillar compositional ratio of muscle fibers intact, thus preserving their functional integrity. Although strength is compromised as a consequence of myofibrillar degradation and endurance is compromised as a consequence of mitochondrial loss, the coordinated action of the two degradation systems allows the muscle to maintain balanced function under adverse conditions.

Author Disclosure: S.N.A.H. does not have a financial relationship with a commercial entity that has an interest in the subject of this manuscript. M.M. does not have a financial relationship with a commercial entity that has an interest in the subject of this manuscript. I.S. does not have a financial relationship with a commercial entity that has an interest in the subject of this manuscript. H.C.K. does not have a financial relationship with a commercial entity that has an interest in the subject of this manuscript. T.V. does not have a financial relationship with a commercial entity that has an interest in the subject of this manuscript. F.M. has received advisory board fees from Boehringer Ingelheim and GSK (both $\$ 1,001-\$ 5,000$ ); he has received lecture fees from Boehringer Ingelheim, GSK, and AstraZeneca (all $\$ 1,001-\$ 5,000$ ); he has received industrysponsored grants from Boehringer-Ingelheim, GSK, AstraZeneca, and Novartis (all $\$ 50,001-\$ 100,000$ ). I.B. does not have a financial relationship with a commercial entity that has an interest in the subject of this manuscript. R.C. does not have a financial relationship with a commercial entity that has an interest in the subject of this manuscript. S.B.G. does not have a financial relationship with a commercial entity that has an interest in the subject of this manuscript. P.M. does not have a financial relationship with a commercial entity that has an interest in the subject of this manuscript. G.D. does not have a financial relationship with a commercial entity that has an interest in the subject of this manuscript. S.M. does not have a financial relationship with a commercial entity that has an interest in the subject of this manuscript. S.J. does not have a financial relationship with a commercial entity that has an interest in the subject of this manuscript. B.J.P. does not have a financial relationship with a commercial entity that has an interest in the subject of this manuscript. P.G. does not have a financial relationship with a commercial entity that has an interest in the subject of this manuscript.

\section{References}

1. Vassilakopoulos T, Petrof BJ. Ventilator-induced diaphragmatic dysfunction. Am J Respir Crit Care Med 2004;169:336-341.

2. Capdevila X, Lopez S, Bernard N, Rabischong E, Ramonatxo M, Martinazzo G, Prefaut C. Effects of controlled mechanical ventilation 
on respiratory muscle contractile properties in rabbits. Intensive Care Med 2003;29:103-110.

3. Le BG, Viires N, Boczkowski J, Seta N, Pavlovic D, Aubier M. Effects of mechanical ventilation on diaphragmatic contractile properties in rats. Am J Respir Crit Care Med 1994;149:1539-1544.

4. Sassoon CS, Caiozzo VJ, Manka A, Sieck GC. Altered diaphragm contractile properties with controlled mechanical ventilation. J Appl Physiol 2002;92:2585-2595.

5. Radell P, Edstrom L, Stibler H, Eriksson LI, Ansved T. Changes in diaphragm structure following prolonged mechanical ventilation in piglets. Acta Anaesthesiol Scand 2004;48:430-437.

6. Powers SK, Shanely RA, Coombes JS, Koesterer TJ, McKenzie M, Van GD, Cicale M, Dodd SL. Mechanical ventilation results in progressive contractile dysfunction in the diaphragm. J Appl Physiol 2002;92: 1851-1858.

7. Yang L, Luo J, Bourdon J, Lin MC, Gottfried SB, Petrof BJ. Controlled mechanical ventilation leads to remodeling of the rat diaphragm. Am J Respir Crit Care Med 2002;166:1135-1140.

8. Bernard N, Matecki S, Py G, Lopez S, Mercier J, Capdevila X. Effects of prolonged mechanical ventilation on respiratory muscle ultrastructure and mitochondrial respiration in rabbits. Intensive Care Med 2003;29: 111-118.

9. Racz GZ, Gayan-Ramirez G, Testelmans D, Cadot P, De PK, Zador E, Wuytack F, Decramer M. Early changes in rat diaphragm biology with mechanical ventilation. Am J Respir Crit Care Med 2003;168:297-304.

10. Anzueto A, Peters JI, Tobin MJ, de los Santos R, Seidenfeld JJ, Moore G, Cox WJ, Coalson JJ. Effects of prolonged controlled mechanical ventilation on diaphragmatic function in healthy adult baboons. Crit Care Med 1997;25:1187-1190.

11. Gayan-Ramirez G, De PK, Cadot P, Decramer M. Detrimental effects of short-term mechanical ventilation on diaphragm function and IGFI mRNA in rats. Intensive Care Med 2003;29:825-833.

12. Watson AC, Hughes PD, Louise HM, Hart N, Ware RJ, Wendon J, Green M, Moxham J. Measurement of twitch transdiaphragmatic, esophageal, and endotracheal tube pressure with bilateral anterolateral magnetic phrenic nerve stimulation in patients in the intensive care unit. Crit Care Med 2001;29:1325-1331.

13. Laghi F, Cattapan SE, Jubran A, Parthasarathy S, Warshawsky P, Choi YS, Tobin MJ. Is weaning failure caused by low-frequency fatigue of the diaphragm? Am J Respir Crit Care Med 2003;167:120-127.

14. Chang AT, Boots RJ, Brown MG, Paratz J, Hodges PW. Reduced inspiratory muscle endurance following successful weaning from prolonged mechanical ventilation. Chest 2005;128:553-559.

15. Knisely AS, Leal SM, Singer DB. Abnormalities of diaphragmatic muscle in neonates with ventilated lungs. $J$ Pediatr 1988;113:1074-1077.

16. Levine S, Nguyen T, Taylor N, Friscia ME, Budak MT, Rothenberg P, Zhu J, Sachdeva R, Sonnad S, Kaiser LR, et al. Rapid disuse atrophy of diaphragm fibers in mechanically ventilated humans. $N$ Engl J Med 2008;358:1327-1335.

17. Shanely RA, Van GD, DeRuisseau KC, Zergeroglu AM, McKenzie MJ, Yarasheski KE, Powers SK. Mechanical ventilation depresses protein synthesis in the rat diaphragm. Am J Respir Crit Care Med 2004;170: 994-999.

18. Shanely RA, Zergeroglu MA, Lennon SL, Sugiura T, Yimlamai T, Enns D, Belcastro A, Powers SK. Mechanical ventilation-induced diaphragmatic atrophy is associated with oxidative injury and increased proteolytic activity. Am J Respir Crit Care Med 2002;166:1369-1374.

19. McClung JM, Kavazis AN, DeRuisseau KC, Falk DJ, Deering MA, Lee Y, Sugiura T, Powers SK. Caspase-3 regulation of diaphragm myonuclear domain during mechanical ventilation-induced atrophy. Am J Respir Crit Care Med 2007;175:150-159.

20. Zhu E, Sassoon CS, Nelson R, Pham HT, Zhu L, Baker MJ, Caiozzo VJ. Early effects of mechanical ventilation on isotonic contractile properties and MAF-box gene expression in the diaphragm. $J$ Appl Physiol 2005;99:747-756.

21. Maes K, Testelmans D, Powers S, Decramer M, Gayan-Ramirez G. Leupeptin inhibits ventilator-induced diaphragm dysfunction in rats. Am J Respir Crit Care Med 2007;175:1134-1138.

22. Solomon V, Goldberg AL. Importance of the ATP-ubiquitin-proteasome pathway in the degradation of soluble and myofibrillar proteins in rabbit muscle extracts. J Biol Chem 1996;271:26690-26697.

23. Scott SV, Klionsky DJ. Delivery of proteins and organelles to the vacuole from the cytoplasm. Curr Opin Cell Biol 1998;10:523-529.

24. Bechet D, Tassa A, Taillandier D, Combaret L, Attaix D. Lysosomal proteolysis in skeletal muscle. Int J Biochem Cell Biol 2005;37:20982114.
25. Mammucari C, Milan G, Romanello V, Masiero E, Rudolf R, Del PP, Burden SJ, Di LR, Sandri C, Zhao J, et al. FoxO3 controls autophagy in skeletal muscle in vivo. Cell Metab 2007;6:458-471.

26. Zhao J, Brault JJ, Schild A, Cao P, Sandri M, Schiaffino S, Lecker SH Goldberg AL. FoxO3 coordinately activates protein degradation by the autophagic/lysosomal and proteasomal pathways in atrophying muscle cells. Cell Metab 2007;6:472-483.

27. Dobrowolny G, Aucello M, Rizzuto E, Beccafico S, Mammucari C, Boncompagni S, Belia S, Wannenes F, Nicoletti C, Del PZ, et al. Skeletal muscle is a primary target of SOD1G93A-mediated toxicity. Cell Metab 2008;8:425-436.

28. Sandri M, Sandri C, Gilbert A, Skurk C, Calabria E, Picard A, Walsh K, Schiaffino S, Lecker SH, Goldberg AL. Foxo transcription factors induce the atrophy-related ubiquitin ligase atrogin-1 and cause skeletal muscle atrophy. Cell 2004;117:399-412.

29. Bergstrom J. Percutaneous needle biopsy of skeletal muscle in physiological and clinical research. Scand J Clin Lab Invest 1975:35:609-616.

30. Mofarrahi M, Brandes RP, Gorlach A, Hanze J, Terada LS, Quinn MT, Mayaki D, Petrof B, Hutchinson DS. Regulation of proliferation of skeletal muscle precursor cells by NADPH oxidase. Antioxid Redox Signal 2008;10:559-574.

31. Barreiro E, Gea J, Di Falco M, Kriazhev L, James S, Hussain SN Protein carbonyl formation in the diaphragm. Am J Respir Cell Mol Biol 2005;32:9-17.

32. Armitage P, Berry G, Matthews JNS. Statistical methods in medical research, 4th ed. Hoboken, NJ: Wiley InterScience; 2008

33. He C, Klionsky DJ. Regulation mechanisms and signaling pathways of autophagy. Annu Rev Genet 2009;43:67-93.

34. Belperio JA, Keane MP, Lynch JP III, Strieter RM. The role of cytokines during the pathogenesis of ventilator-associated and ventilator-induced lung injury. Semin Respir Crit Care Med 2006;27:350364.

35. Amado JA, Lopez-Espadas F, Vazquez-Barquero A, Salas E, Riancho JA, Lopez-Cordovilla JJ, Garcia-Unzueta MT. Blood levels of cytokines in brain-dead patients: relationship with circulating hormones and acute-phase reactants. Metabolism 1995;44:812-816.

36. McClung JM, Van GD, Whidden MA, Falk DJ, Kavazis AN, Hudson MB, Gayan-Ramirez G, Decramer M, DeRuisseau KC, Powers SK Apocynin attenuates diaphragm oxidative stress and protease activation during prolonged mechanical ventilation. Crit Care Med 2009;37: 1373-1379.

37. DeRuisseau KC, Kavazis AN, Deering MA, Falk DJ, Van GD Yimlamai T, Ordway GA, Powers SK. Mechanical ventilation induces alterations of the ubiquitin-proteasome pathway in the diaphragm. J Appl Physiol 2005;98:1314-1321.

38. Wing SS, Banville D. 14-kDa ubiquitin-conjugating enzyme: structure of the rat gene and regulation upon fasting and by insulin. Am J Physio 1994;267:E39-E48.

39. Li YP, Chen Y, Li AS, Reid MB. Hydrogen peroxide stimulates ubiquitin-conjugating activity and expression of genes for specific E2 and E3 proteins in skeletal muscle myotubes. Am J Physiol Cell Physiol 2003;285:C806-C812.

40. Voisin L, Breuille D, Combaret L, Pouyet C, Taillandier D, Aurousseau E, Obled C, Attaix D. Muscle wasting in a rat model of long-lasting sepsis results from the activation of lysosomal, $\mathrm{Ca}^{2+}$-activated, and ubiquitin-proteasome proteolytic pathways. J Clin Invest 1996;97: 1610-1617.

41. McClung JM, Judge AR, Powers SK, Yan Z. p38 MAPK links oxidative stress to autophagy-related gene expression in cachectic muscle wasting. Am J Physiol Cell Physiol 2009;298:C542-C549.

42. Zergeroglu MA, McKenzie MJ, Shanely RA, Van Gammeren D, DeRuisseau KC, Powers SK. Mechanical ventilation-induced oxidative stress in the diaphragm. J Appl Physiol 2003;95:1116-1124.

43. Jaber S, Sebbane M, Koechlin C, Hayot M, Capdevila X, Eledjam JJ, Prefaut C, Ramonatxo M, Matecki S. Effects of short vs. prolonged mechanical ventilation on antioxidant systems in piglet diaphragm. Intensive Care Med 2005;31:1427-1433.

44. Falk DJ, DeRuisseau KC, Van Gammeren DL, Deering MA, Kavazis AN, Powers SK. Mechanical ventilation promotes redox status alterations in the diaphragm. J Appl Physiol 2006;101:1017-1024.

45. Sandri M. Signaling in muscle atrophy and hypertrophy. Physiology (Bethesda) 2008;23:160-170.

46. Tran H, Brunet A, Griffith EC, Greenberg ME. The many forks in FOXO's road. Sci STKE 2003;(172):RE5.

47. Favier FB, Costes F, Defour A, Bonnefoy R, Lefai E, Bauge S, Peinnequin A, Benoit H, Freyssenet DG. Down-regulation of Akt/ 
mammalian target of rapamycin pathway in skeletal muscle is associated with increased REDD1 expression in response to chronic hypoxia. Am J Physiol Regul Integr Comp Physiol 2010;298:R1659R1666.

48. Bodine SC, Stitt TN, Gonzalez M, Kline WO, Stover GL, Bauerlein R, Zlotchenko E, Scrimgeour A, Lawrence JC, Glass DJ, et al. Akt/ mTOR pathway is a crucial regulator of skeletal muscle hypertrophy and can prevent muscle atrophy in vivo. Nat Cell Biol 2001;3:1014 1019.

49. Sandri M, Lin J, Handschin C, Yang W, Arany ZP, Lecker SH, Goldberg AL, Spiegelman BM. PGC-1alpha protects skeletal muscle from atrophy by suppressing FoxO3 action and atrophy-specific gene transcription. Proc Natl Acad Sci USA 2006;103:16260-16265.

50. Senf SM, Dodd SL, McClung JM, Judge AR. Hsp70 overexpression inhibits NF-kappaB and Foxo3a transcriptional activities and prevents skeletal muscle atrophy. FASEB J 2008;22:3836-3845.

51. McLoughlin TJ, Smith SM, DeLong AD, Wang H, Unterman TG, Esser KA. FoxO1 induces apoptosis in skeletal myotubes in a DNAbinding-dependent manner. Am J Physiol Cell Physiol 2009;297: C548-C555.
52. Lecker SH, Jagoe RT, Gilbert A, Gomes M, Baracos V, Bailey J, Price SR, Mitch WE, Goldberg AL. Multiple types of skeletal muscle atrophy involve a common program of changes in gene expression. FASEB J 2004;18:39-51.

53. McClung JM, Kavazis AN, Whidden MA, DeRuisseau KC, Falk DJ, Criswell DS, Powers SK. Antioxidant administration attenuates mechanical ventilation-induced rat diaphragm muscle atrophy independent of protein kinase B (PKB Akt) signalling. J Physiol 2007;585:203-215.

54. Kamei Y, Miura S, Suzuki M, Kai Y, Mizukami J, Taniguchi T, Mochida K, Hata T, Matsuda J, Aburatani H, et al. Skeletal muscle FOXO1 (FKHR) transgenic mice have less skeletal muscle mass, downregulated Type I (slow twitch/red muscle) fiber genes, and impaired glycemic control. J Biol Chem 2004;279:41114-41123.

55. Yamazaki Y, Kamei Y, Sugita S, Akaike F, Kanai S, Miura S, Hirata Y, Troen BR, Kitamura T, Nishino I, et al. The cathepsin L gene is a direct target of FOXO1 in skeletal muscle. Biochem $J$ 2010;427:171-178.

56. Levine B, Klionsky DJ. Development by self-digestion: molecular mechanisms and biological functions of autophagy. Dev Cell 2004;6: 463-477. 